\title{
Design of Zeta Converter with MPPT Algorithm for Solar Photovoltaic Application Integrated with Battery
}

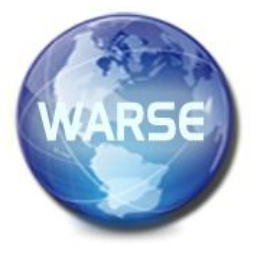

\author{
Kumuthawathe Ananda-Rao ${ }^{1}$, Tunku Muhammad Nizar Tunku Mansur ${ }^{2}$, \\ Nor Hanisah Baharudin ${ }^{3}$,Yazan Matar ${ }^{4}$ \\ ${ }^{1}$ Faculty of Electrical Engineering Technology, University Malaysia Perlis, Malaysia, \\ kumuthawathe@unimap.edu.my \\ ${ }^{2}$ Faculty of Electrical Engineering Technology, University Malaysia Perlis, Malaysia, \\ tunkunizar@unimap.edu.my \\ ${ }^{3}$ Faculty of Electrical Engineering Technology, University Malaysia Perlis, Malaysia, \\ norhanisah@unimap.edu.my \\ ${ }^{4}$ Faculty of Electrical Engineering Technology, University Malaysia Perlis, Malaysia, \\ Yazan.mattar@hotmail.com
}

\begin{abstract}
This paper presents the design of a zeta converter with Maximum Power Point Tracking (MPPT) algorithm for solar Photovoltaic (PV) application integrated with battery. As the power produced from PV system is stochastic in nature due to the variation of solar irradiation and cell temperature throughout the day, a DC-DC converter with MPPT algorithm has been recognized as the primary solution. Zeta converter is chosen in this work due to its significantly lower output voltage ripple. The full model was designed using Matlab Simulink software where the performance of the zeta converter and PV module with MPPT algorithm will be analysed. Perturb and Observe (P\&O) MPPT algorithm is used in this work due to its easiness of implementation with outstanding performance. From the simulation results, the designed zeta converter with $\mathrm{P} \& \mathrm{O}$ MPPT algorithm able to maintain the maximum efficiency to supply the load under constant and variable irradiance levels by modulating the zeta converter's duty cycle.
\end{abstract}

Key words :Charge controller, Perturb and Observe, Solar Photovoltaic, Zeta converter.

\section{INTRODUCTION}

Solar Photovoltaic (PV) has emerged as a most popular approach for generating power compare to other Renewable Energy (RE) resources, in substituting conventional sources due to several factors like the falling prices of silicon and PV modules, technological advancements in large scale manufacturing and governmental incentives [1]. However, the output characteristics of PV module are non-linear and the amount of power generated by the PV panel depends on the solar irradiance and the cell temperature which will cause the output power to fluctuate [2]. Thus, to overcome this issue and to extract maximum power from PV modules, DCDC converters integrated with the Maximum Power Point Tracking (MPPT) algorithm is needed to be employed as a charge controller in the PV system [3]-[4].
There are numerous types of research works have been conducted over the years in the aspect of MPPT algorithm and DC-DC converters to achieve the maximum efficiency of PV system. A. Ambikapathy et. al [5] compared and analysed the performance of DC-DC converters for MPPT controller with Perturb and Observe ( $\mathrm{P} \& \mathrm{O})$ algorithm in a grid-connected system. Based on their study thru simulation in Matlab, zeta converter gives the best output to achieve the maximum output power from PV module and compatible with the commercial grid. Meanwhile, simulation and experimental study of zeta converter with MPPT are analysed under static and dynamic conditions for small power applications by A. Raj et. al [6]. On the other hand, M.Kaouane et.al [7] presented a method to maximize the generated power outgoing from PV generators by transferring the energy to the load using zeta converter and controlling it with Incremental-Conductance MPPT algorithm.

Furthermore, a novel zeta converter for charging the battery by extracting the maximum power from PV panels, based on MPPT algorithm was presented by P. Suresh et.al [8]. Meanwhile, A. Malhotra et.al [9] proposed a zeta converter to regulate and boost the voltage obtained from PV array along with solar energy system that consists of PV arrays, inverters and single-phase asynchronous motor. P\&O MPPT algorithm was used together with PID controller to control the switching of the DC-DC converter in their work. Whereas, M.Birane et.al [10] presented a MPPT system using different topologies of power converters to find the best in terms of efficiency and produced energy.

Consequently, in this work, a zeta converter is designed with MPPT algorithm as a charge controller for PV system integrated with battery. The system will track the Maximum Power Point (MPP) of the solar PV module by modulating the zeta converter's duty cycle, thereby, optimizing the power output of the PV panel. This paper is organized into 6 sections. Section 1 introduces the overall system. Section 2 presents the design of zeta converter and Section 3 is about the P\&O MPPT algorithm. A broad description of the 
controller design is given in Section 4, where the details of parameters used, block diagram and system design are provided. Section 5 comprises simulation results and discussion, while Section 6 presents the conclusion.

\section{ZETA CONVERTER}

DC-DC converters are power electronic circuits that convert a DC voltage from one level to another to provide a regulated output. In this work, Zeta converter is selected compared to other conventional DC-DC converters due to the advantages of soft starting, continuous output current, boundless region for MPPT, low ripple input, and output currents [11].Zeta converter is configured based on buck converter and it can either step-up or down the output voltage depending on the duty cycle of the switch used in the circuit [12]-[13].

Zeta converter is similar to the Cuk and Sepic converter where it can produce an output voltage that is either greater or less than the input voltage with no polarity reverse. The significant lower output voltage ripple is the one that distinguishes zeta converter from the other two mentioned converters. The output voltage ripple is described as an undesired power loss. Moreover, the output voltage ripple is related to the switching frequency and the capacitor capacitance, wherelarger capacitance is required in the designto reduce the output voltage ripple [14].

Figure 1 shows the equivalent circuit of zeta converter. Zeta converter consists of two inductors and a series capacitor. The input capacitor exists to filter the input voltage and the output capacitor filters the output voltage. In order to design the zeta converter, some assumptions need to be made before proceeding with the analysis [12]:

- The circuit is operating in a steady state.

- The inductor current is operating in contentious mode (always positive) (CCM).

- The switching period is $\mathrm{T}$; the switch is closed for time DT and open for time (1-D) *T where D is the duty cycle.

- The passive components are assumed to be ideal.

- The two coupled inductors are identical.

Figure 2 shows the equivalent circuit of the zeta converter when the switch Q1 is closed (on). When Q1 is on, the energy flowing from the input source will be stored in L1a, $\mathrm{L} 1 \mathrm{~b}$ and $\mathrm{C}_{\mathrm{c}}$. L1b also will provide the output current of the circuit [14]-[15].

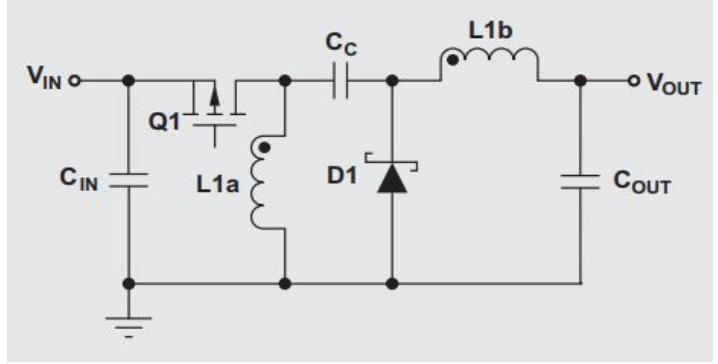

Figure 1: Zeta converter equivalent circuit [12],[14]

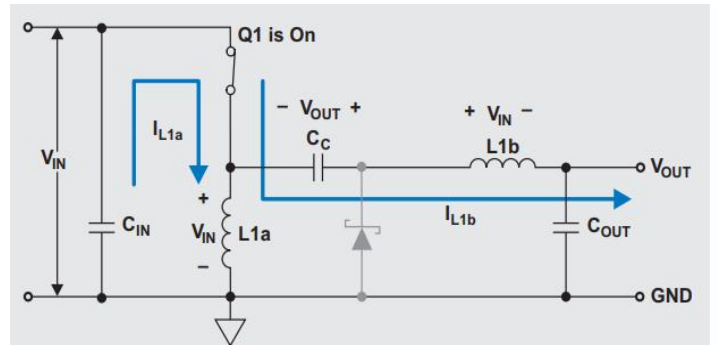

Figure 2: Equivalent circuit of zeta converter when Q1 is on [12],[14]

By implying KVL in the left loop in Figure 2:

$$
V_{I N}=V_{L 1 a(S W, \text { closed })}(1)
$$

where, the inductor voltage is described as the product of the inductor inductance and the derivative of the inductor current in respect to time:

$$
V_{L 1 a}(\text { SW,closed })=L \frac{d I_{L 1 a}}{d t}(2)
$$

In contrast, when Q1 is off (opened), the energy flows the supply will no longer flow in the circuit as shown in Figure 3 . Instead, the energy flow will be created from the energy stored in the components [14]-[15].By applying KVL in the loop that contains $\mathrm{L} 1 \mathrm{a}$ and $\mathrm{C}_{\mathrm{c}}$ :

$$
+V_{L 1 a}+V_{C c}=0
$$

By applying $\mathrm{KVL}$ in the loop that contains $\mathrm{L} 1 \mathrm{~b}$ and $\mathrm{C}_{\text {out }}$ :

$$
\begin{aligned}
& +V_{L 1 b}+V_{\text {out }}=0 \\
& V_{L 1 b}=-V_{\text {out }}
\end{aligned}
$$

Since the two coupled inductors are assumed to be idealand identical:

$$
\begin{aligned}
& \mathrm{V}_{\mathrm{L} 1 \mathrm{~b}}=\mathrm{V}_{\mathrm{L} 1 \mathrm{a}} \\
& \left.V_{\text {L1a }}(6) \text { (SW,opened }\right) \\
& =-V_{\text {out }}
\end{aligned}
$$

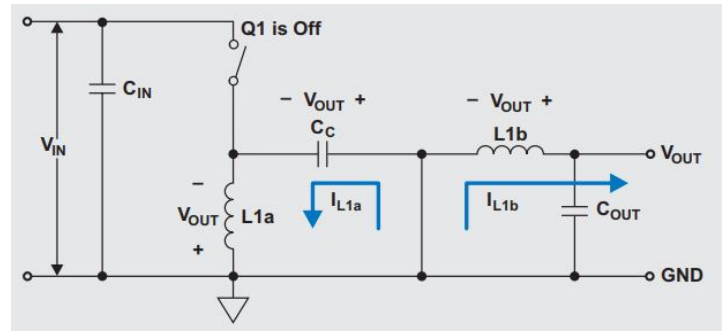

Figure 3: Equivalent circuit of zeta converter when Q1 is off $[12],[14]$ 
However, practically the coupled inductors will not have the same inductance. And the ripple current will not be equal. But, assumption are made that the both inductors are ideal and identical [14], [16].

For continues current mode (CCM):

$\left(V_{L 1 a(S W, \text { opened })}\right)(1-D) T+V_{L 1 a(S W, \text { closed })}(D T)=0(8)$

where $\mathrm{D}$ is the duty cycle.

After simplifying the resultant,(8) will be:

$$
\begin{gathered}
-V_{\text {out }}(1-D) T+V_{I N}(D T)=0(9) \\
V_{\text {out }}=V_{I N}\left(\frac{D}{1-D}\right)
\end{gathered}
$$

The duty cycle can be expressed as:

$$
D=\frac{V_{\text {out }}}{V_{\text {out }}+V_{I N}}
$$

The result is similar to that of buck-boost and Cuk converter equations, with the important distinction that there is no polarity reversal between the input and the output voltages. The ability to have an output voltage greater or less than the input with no polarity reversal makes this converter suitable for supplying the battery of the solar PV system [14].

Since, the inductor voltage is described as:

$V_{L 1 a(S W, \text { closed })}=L \times\left(\frac{d I_{L 1 a}}{d t}\right)=L \times\left(\frac{\Delta I_{L 1 a}}{D T}\right)(12)$

where, $\Delta \mathrm{I}_{\mathrm{Lla}}$ is the ripple current of the inductor and $F_{(s w)}$ is the switching frequency. The (12) can be simplified to:

$$
V_{I N}=L\left(\frac{\Delta I_{L 1 a}}{D T}\right)
$$

Solving for $\mathrm{L}_{\min }$ :

$$
L_{\text {min }}=V_{\text {in }}\left(\frac{D}{f_{s w} \times \Delta I_{L 1 a}}\right)(14)
$$

where $f_{s w}=\frac{1}{T}$.

Since both inductors has the same inductance value:

$$
L_{1 a \text { min }}=L_{1 b \min }=\frac{1}{2} V_{\text {in }}\left(\frac{D}{f_{s w} \times \Delta I_{L 1 a}}\right)(15)
$$

The current at each inductor is described as the following:

$$
\Delta I_{L 1 a}=I_{\text {out }} \times \frac{D}{1-D}+\frac{\Delta I L}{2}(16)
$$

$$
\Delta I_{L 1 b}=I_{\text {out }}+\frac{\Delta I L}{2}(17)
$$

The output ripple voltage of the converter is defined as:

$$
\Delta V_{\text {Cout }}=\frac{\Delta I_{L 1 b}}{8 \times C_{\text {Out }} \times f_{\text {sw }}}(18)
$$

Moreover, the twocapacitors used in the design beside the output capacitor are assumed to have the same capacitance. Thus, the ripple voltage across each capacitor is:

$$
\Delta V_{\text {in }}=\Delta V_{C c}=\frac{D \times I_{\text {out }}}{C \times f_{\text {sw }}}(19)
$$

where $\mathrm{C}$ is the capacitance of the capacitor and $\Delta V$ is the ripple voltage across the capacitor.

\section{PERTURBANDOBSERVE (P\&O) MPPT ALGORITHM}

MPPT is based on moving the operating PV voltageorcurrent to regularly supply the load with the maximum power.Although there are large numbers of MPPT techniques have been developed to increase the PV system efficiency, $\mathrm{P} \& \mathrm{O}$ algorithm is used widely due to its easiness of implementation with the outstanding performance [17][18].

$\mathrm{P} \& \mathrm{O}$ method is based on the trial and error process in finding and tracking the MPP. At every cycle, the tracking measures PV current and voltage and deduces the actual PV power, then perturbs the operating point by sweeping the operating voltage and monitoring the variation of power [19]-[20].Table 1 summarizes the P\&O MPPT algorithm. This process will keep operating until the MPP is achieved. This technique is considered simple and efficient compared with other methods implemented in MPPT. However, its failure to track MPP when there is a big change in the isolation level as well as the continuous oscillation around MPP is the drawback of this method [21]-[23].

Table 1: P\&O MPPT algorithm summary

\begin{tabular}{|c|c|c|}
\hline Perturbation & Change in power & Next perturbation \\
\hline Positive & Positive & Positive \\
\hline Positive & Negative & Negative \\
\hline Negative & Positive & Negative \\
\hline Negative & Negative & Positive \\
\hline
\end{tabular}

\section{SYSTEM DESIGN}

In this work, a zeta converter is designed with MPPT algorithm for solar PV application integrated with battery using Matlab Simulink. Figure 4 shows the overall block diagram of the design. PV module is used to supply energy to the zeta converter, besides being measured the current and voltage to be fed to the MPPT algorithm. Once the input parameters are measured, the $\mathrm{D}$ will be set to achieve the 
MPP from the PV power input. From the D, a Pulse Width Modulation (PWM) will be generated to be fed to the zeta converter to control the switching time. Finally, the output of the converter will supply the load, which is lead acid battery in this work.

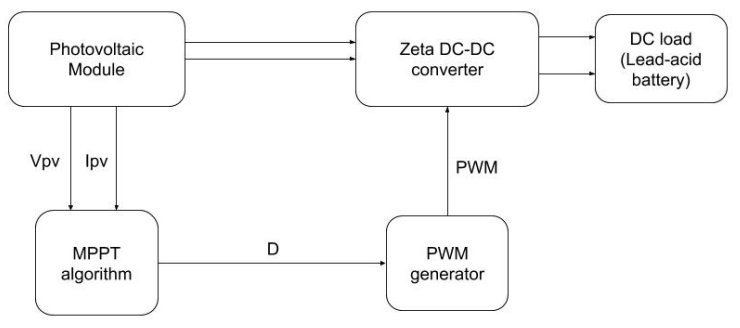

Figure 4: Overall block diagram

The PV module used in this design is Kyocera KC130TM module, obtained from Matlab Sim Power System block set. The maximum power of this module is $130 \mathrm{~W}$ with a maximum output voltage of $17.6 \mathrm{~V}$. Thus, this PV module will be able to supply a $12 \mathrm{~V}$ nominal voltage lead acid battery that is connected by 6 cells in series, which are used in this design as a load [23].

The zeta converter consists of two inductors, two capacitors and a diode. Assuming the inductors used in the design are coupled, the value of inductor is determined using (15). However, since the design in this work does not use a coupled inductor, the value of each inductor is described as:

$$
L_{1 a \min }=L_{1 b \min }=V_{i n}\left(\frac{D}{f_{s w} \times \Delta I_{L 1 a}}\right)(20)
$$

The switching frequency in the design is assumed to be 50 $\mathrm{kHz}$. The switching frequency selection is based on the application in which the switch is used for such as inverter and converter passive switching. The input capacitor and series capacitor ripple voltage are assumed to be $10 \%$ of the input voltage from the PV panel [23].Hence, the capacitance is described as:

$$
C_{\text {in }}=C_{c}=\frac{D \times I_{\text {out }}}{\Delta V \times f_{\text {sw }}}
$$

The output capacitor capacitance is determined by:

$$
C_{\text {out }}=\frac{\Delta I_{L 1 b}}{8 \times \Delta V_{\text {Cout }} \times f_{\text {sw }}}(22)
$$

where, $\Delta V_{\text {Cout }}$ is the output ripple voltage and it is assumed to be $25 \mathrm{mV}$. The resistive load is assumed to be $3 \mathrm{ohms}$ to achieve an output voltage from the converter of $19 \mathrm{~V}$, so that, the converter can supply the battery. By using (20) (22) with the PV module parameter, the components of the zeta converter can be summarized as in Table 2 .
Table 2: Zeta converter parameter selection

\begin{tabular}{|c|c|}
\hline $\begin{array}{c}\text { Paramet } \\
\text { er }\end{array}$ & Value \\
\hline Vin & $17.6 \mathrm{~V}$ \\
\hline Iin & 7.39 \\
\hline RL & 3 ohms \\
\hline Cin & $40 \mu \mathrm{F}$ \\
\hline Cout & $733 \mu \mathrm{F}$ \\
\hline Cc & $40 \mu \mathrm{F}$ \\
\hline L1a & $126 \mu \mathrm{H}$ \\
\hline L1b & $126 \mu \mathrm{H}$ \\
\hline
\end{tabular}

The overall Simulink model for MPPT algorithm implemented with zeta converter for PV application integrated with lead acid battery is presented in Figure 5.Based on the PV module irradiance and temperature, the controlled current source value will be adjusted while the shunt and series resistors value are determined by the PV module model number. In this design, sum blocks are used to measure and compare the PV module input with the previous measurement. Whereas, three switch cases will control the duty cycle by either increasing or decreasing it to achieve the desired MPP. Next, any fluctuation in the duty cycle signalwill be eliminated using D-sample block. At the same time, the saturation block will limit the value of the duty cycle from 0 to 0.9 . Meanwhile, the parameters of the battery such as nominal voltage and the fully charged voltage are controlled by the model block. The controlled current and voltage will be fed to the terminal through a resistor which represents the internal resistance of the battery.

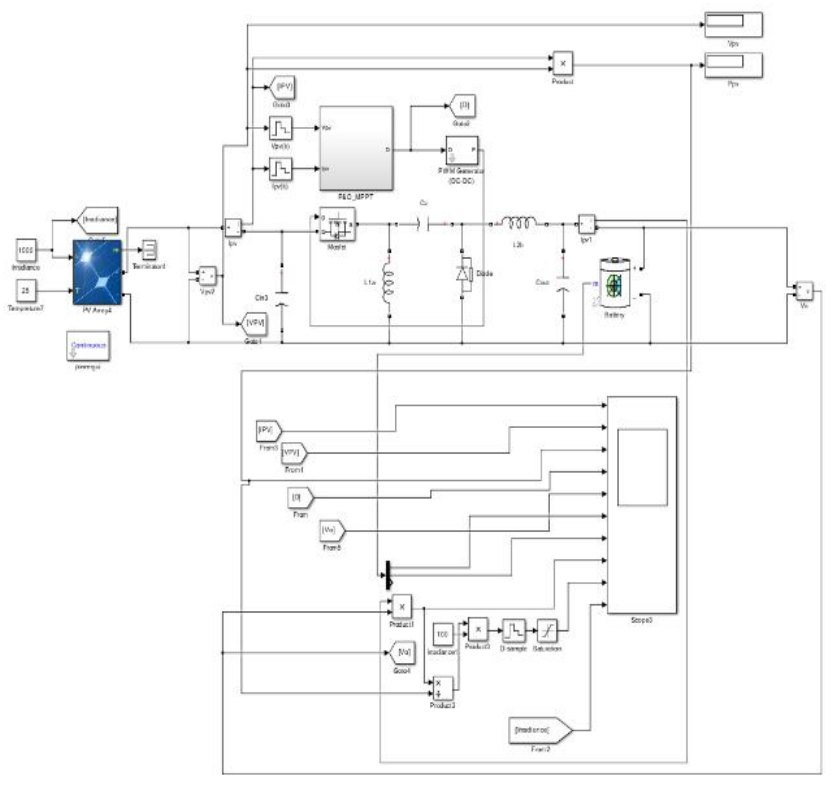

Figure 5: Overall Simulink model

\section{RESULTS AND DISCUSSION}

In this section, the designed zeta converter with MPPT algorithm is assessed through simulation. However, before proceeding to the performance simulation, design validation 
needs to be performed first. Thus, this design is validated by comparing MPP obtained by the system with the MPP from the Kyocera Solar KC130TM PV module datasheet at each level of irradiance.Figure 6 presents the MPP comparison where it can be seen clearly that the designed controller is reliable for further performance simulation.

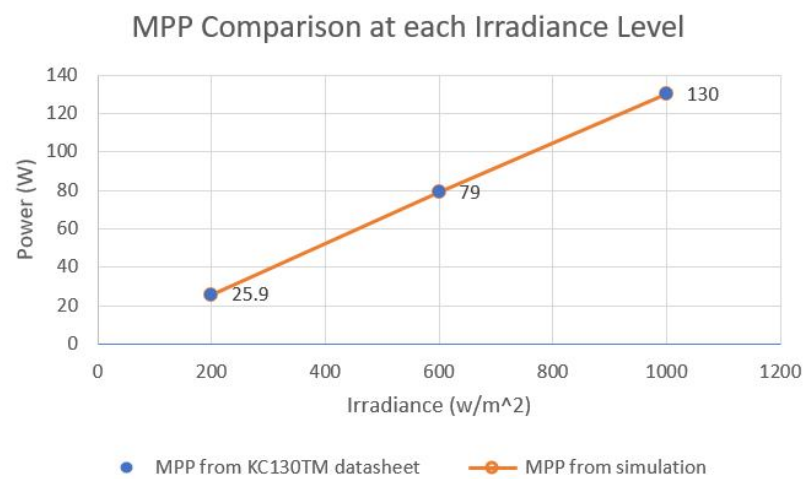

Figure 6: MPP comparison for design validation

Simulation was performed on the designed controller to evaluate the zeta converter and PV module with MPPT algorithm performance under constant and variable irradiance levels. Figure 7 presents the simulation results with constant irradiance inputto the PV module. As shown in Figure 7 , the system was able to maintain efficiency by adjusting the duty cycle to track the MPP. The efficiency variation between $82 \%$ to $84 \%$ was due to the $\mathrm{P} \& \mathrm{O}$ tracking method weakness, as the system will not be able to track the exact MPP. Instead, it will fluctuate around the MPP within three steps as shown in Figure 7.

In addition, as shown in Figure 8, the PV module voltage was kept constant at the MPP with the adjustment of the duty cycle. However, the battery voltage dropped when it reached the maximum voltage at $12 \mathrm{~V}$. Thus, the system was able to extract the MPP at a constant level of irradiance but could not maintain the output voltage and track the MPP at the same time. Moreover, the PV module current is kept fluctuating with the duty cycle and the MPP to maintain the optimal operation. Meanwhile, the battery current kept increasing since the battery voltage decreased. It is worth mentioning that the battery current is negative because the battery is charging.

Furthermore, Figure 9 presents the zeta converter output power and PV module power versus time. As shown in Figure 9, the MPP is maintained throughout the time. The output power also maintained constant throughout the operation to achieve the highest efficiency possible. The output power is $115 \mathrm{~W}$ due to the losses in the system. However, the MPP at $1000 \mathrm{w} / \mathrm{m}^{\wedge} 2$ of irradiance is recorded fluctuating between $128 \mathrm{~W}$ and $130 \mathrm{~W}$ which matches the value in Figure 6.

Next, the designed controller was simulated with variable irradiance levels. As shown in Figure 10, the system was able to track the maximum efficiency with the variable irradiance. However, when the system starts to track the efficiency, it takes time for the duty cycle to be adjusted to the maximum efficiency.

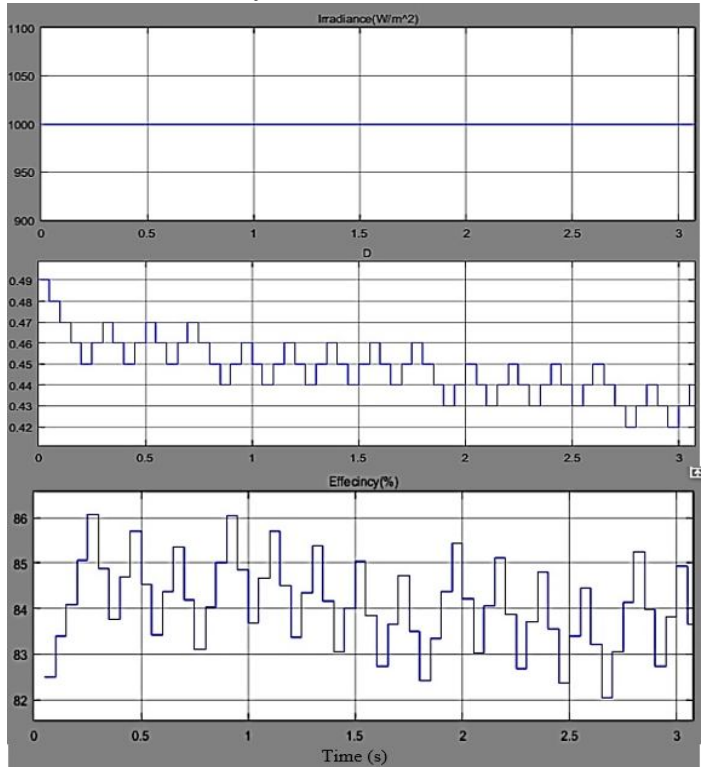

Figure 7: Simulation results with a constant irradiance, duty cycle (D) and zeta converter efficiency versus time

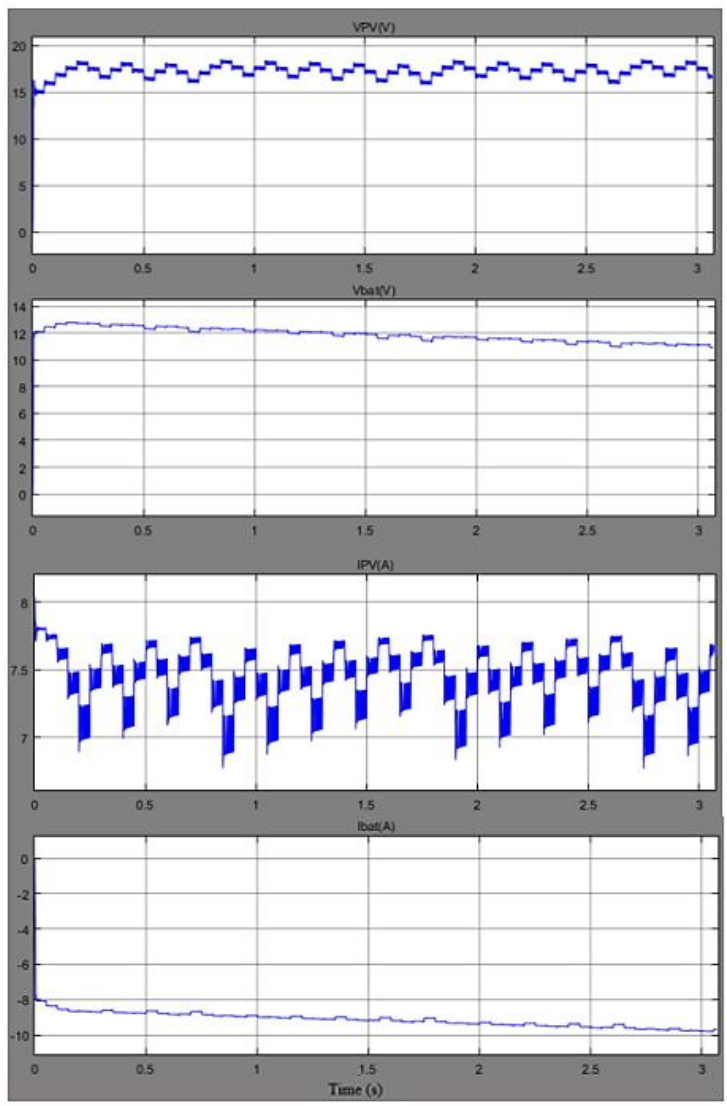

Figure 8: Changes in PV module voltage, battery voltage, PV module current and battery current versus time for constant irradiance 


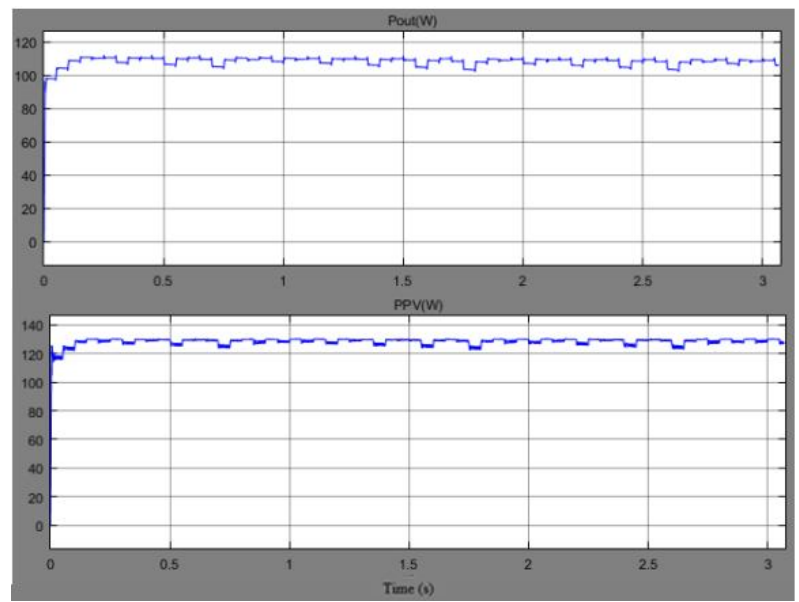

Figure 9:Zeta converter output power and PV module power versus time for constant irradiance input

When the system irradiance drops referring to Figure 10, the PV module voltage and battery voltage also decrease as shown in Figure 11. But, with the MPPT tracking, thePV module voltage and the battery voltage were able to increase to the required amount.Besides that, Figure 11also presents thePV module current and battery current. When the PV module current decreases, the battery current decreases to the same point and vice versa. It can be seen clearly that the system was trying to regulate the fluctuating of the input current, but it takes time to maintain the maximum current from the PV module. Moreover, the tracking algorithm was able to track the MPP at each irradiance variation as shown in Figure 12. The output power is maintained at its maximum with the increment or decrement of the amount of irradiance.

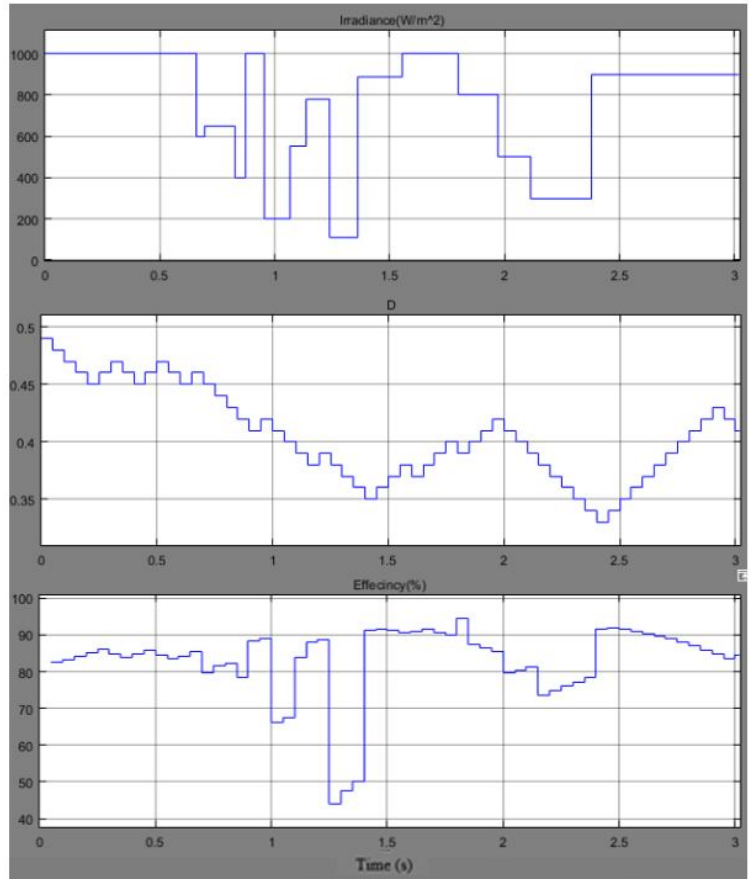

Figure 10: Simulation results with variable irradiance, duty cycle (D) and zeta converter efficiency versus time

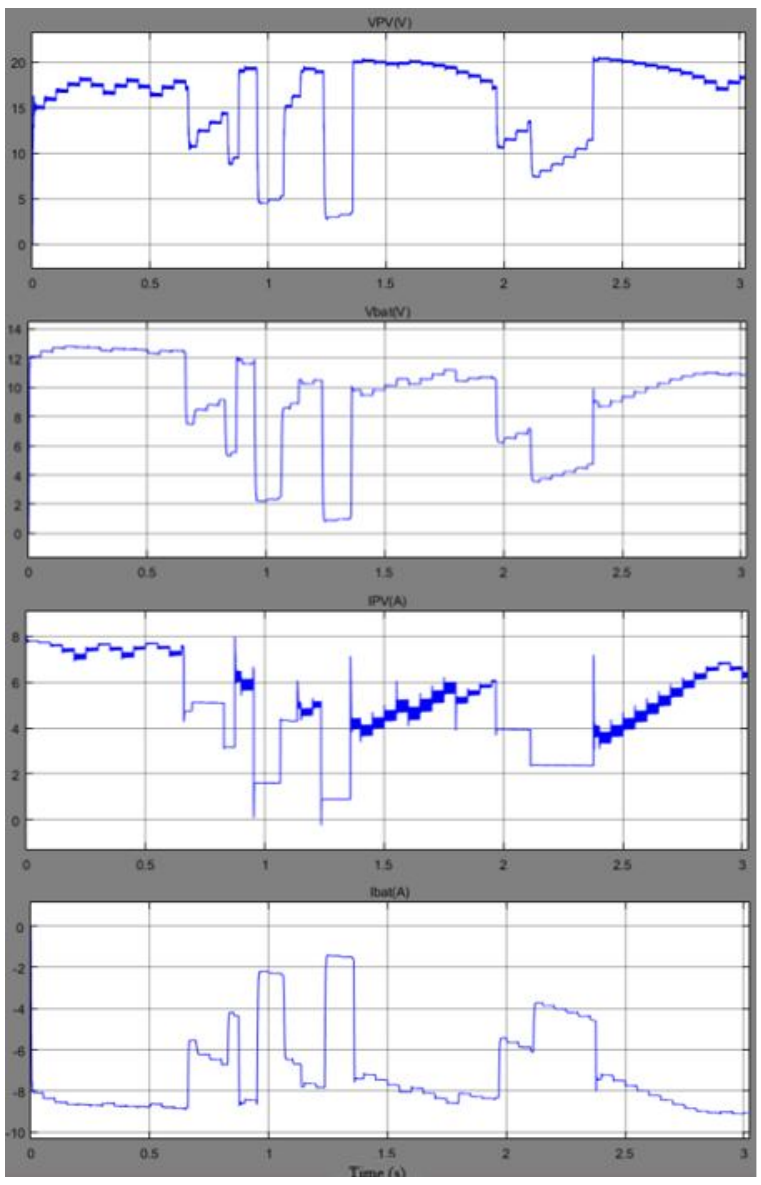

Figure 11: Changes in PV module voltage, battery voltage, PV module current and battery current versus time for variable irradiance

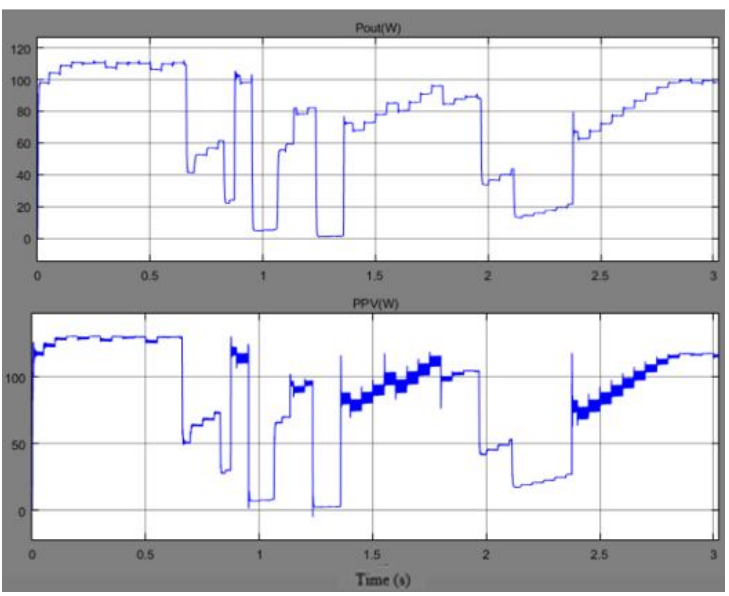

Figure 12:Zeta converter output power and PV module power versus time for variable irradiance input

Based on the simulation results obtained from both constant and variable irradiance levels, the designed zeta converter with P\&O MPPT algorithm with the lead acid battery as the load was able to maintain the maximum efficiency of the system. 


\section{CONCLUSION}

As an alternative to reduce the usage of fossil fuels, solar energy is the substantial RE source that is safe, environmentally friendly, unpolluted and green source of inexhaustible energy. In this paper, the implementation ofzeta converter and P\&O MPPT algorithmhas been verified to extract the MPP by adjusting the duty cycle. Zeta converter has been designed and tested where the converter preformed well under constant and different irradiance levels with the lead acid battery as the load. Overall, the system was able to maintain the maximum efficiency by modulating the zeta converter's duty cycle.However, for better performance, it is recommended to add a second stage DCDC converter with Proportional Integral (PI) controller to satisfy the load demand implemented in the system.

\section{ACKNOWLEDGEMENT}

The authors would like to acknowledge the support from the Internal Social Project Via Research (INSPIRE) Research Grant 2019 under a grant number of UniMAP/PPPI/900100584(1) from Universiti Malaysia Perlis.

\section{REFERENCES}

1. M. Obi and R. Bass.Trends and challenges of gridconnected photovoltaic systems - A review, Renewable and Sustainable Energy Reviews, Vol. 58, pp. 10821094, 2016.

2. M.S. Ibbini and A.H. Adawi. Analysis and design of a Maximum Power Point Tracker for a stand-alone Photo Voltaic system using Simscape, International Journal of Advanced Trends in Computer Science and Engineering, Vol. 8(1), pp. 54-57, Jan-Feb 2019.

3. M.Z. Hossain, N.A. Rahim and J. Selvaraj.Recent progress anddevelopment on power DC-DC converter topology, control, design and applications: A review, Renewable andSustainableEnergy Reviews,Vol. 81, pp. 205-230, 2018.

4. S. Rajalakshmi and S. Titus. Optimal slewing mode converter-based energy management system for Renewable Energy sources, International Journal of Advanced Trends in Computer Science and Engineering, Vol. 9(3), pp. 2493-2502, May-June 2020.

5. A. Ambikapathy, G. Singh and P. Tiwari.Performance of different types of DC-DC converter with P\&O algorithm of MPPT,International Journal of Smart Home, Vol. 10(6), pp. 277-286, 2016.

6. A. Raj, S.R.Arya and J. Gupta. Solar PV array-based DC-DC converter with MPPT for low power applications, Renewable Energy Focus, Vol. 34, pp. 111, July 2020.

7. M. Kaouane, A.Boukhelifa and A.Cheriti. Implementation of Incremental-Conductance MPPT algorithm in a Photovoltaic conversion system based on DC-DC ZETA converter in $8^{\text {th }}$ International Conference on Modelling, Identification and Control, 2016, pp. 612-617.
8. P. Suresh, A. Sureshkumar and P.Vishnuram. Photovoltaic battery charger based on novel zeta converter,International Journal of Pure and Applied Mathematics, Vol. 118(19), pp. 2683-2694, Feb 2018.

9. A. Malhotra, S.Vij, P. Gaur and C. Malhotra.Design, analysis and performance of zeta converter in renewable energy systems inIEEE International Conference on Computing for Sustainable Global Development, 2016, pp. 2487-2491.

10. M. Birane, A.Derrouazin, M.Aillerie, A.Cheknane and C.Larbes.Evaluation and performance of different topologiesof converters with efficient MPPT in a photovoltaic system. Journal of Electrical Systems, 16(3), pp. 308-319, 2020.

11. B. Arundhati, S. Murali and M.V.G. Varaprasad. Solar powered brushless DC motor drive using zeta converter, International Journal of Pure and Applied Mathematics,Vol. 114(8), pp. 81-91, April 2017.

12. A.Admane and H. Naidu. Analysis and design of zeta converter,International Journal for Innovative Research in Multidisciplinary Field, Vol. 4(4), pp. 161167, Apr 2018.

13. H. Parthsarathy, L.Udayakumar and G. Balasubramanian. Modeling and Simulation of PV module and zeta converter inIEEE International Conference on Circuit, Power and Computing Technologies, 2016.

14. Jeff Falin. Designing DC-DC Converters based on ZETA Topology,Analog application Journal, 2010.

15. G. Dileep and S.N. Singh.Selection of non-isolated DC-DC converters for solar photovoltaic system,Renewable and Sustainable Energy Reviews, Vol. 76, pp. 1230-1247, 2017.

16. A.M.S.Al-bayati, S.S.Alharbi, S.S. Alharbi and M. Matin. Design and performance study of a DC-DC ZETA converter with wide bandgap power devices in Proc. of SPIE, 2018, Vol 10754.

17. E. Norouzzadeh, A.A.Ahmad, M. Saeedian, G. Eini and E. Pouresmaeil. Design and implementation of a new algorithm for enhancing MPPT performance in solar cells,Energies, 12(3), pp. 519, 2019.

18. M.L. Azad, P.K. Sadhu and S. Das. (2020). Comparative study between $\mathrm{P} \& \mathrm{O}$ and incremental conduction MPPT techniques- A review in IEEE International Conference on Intelligent Engineering and Management, 2020, pp. 217-222.

19. N. Karami, N.Moubayed and R.Outbib.General review and classification of different MPPT techniques, Renewable and Sustainable Energy Reviews, Vol. 68, pp. 1-18, 2017.

20. P.S. Mali, S.D. Patil, S.D. Pawar, D.B. Kanase and R.B. Madake. Maximum power point tracking along with perturb and observe method in hybrid microgrid,International Journal of Engineering Research \& Technology, Vol. 9(3), pp. 677-682, March 2020.

21. U. Jayashree, R.H.P. Nightingale and S. Divya.Implementation of basic MPPT techniques for zeta converter in 3rd Third International Conference on Science Technology Engineering \& Management, 2017, pp. 601-604. 
22. A.S. Mahdi, A.K.Mahamad, S. Saon, T.Tuwoso, HakkunElmunsyah and S.W. Mudjanarko.Maximum power point tracking using perturb and observe, fuzzy logic and ANFIS, Springer Nature Applied Sciences, 2:89, 2020.
23. K. Ananda-Rao, Y.Matar, N.H. Baharudin, M.A. Ismail and A.M. Abdullah. Design of MPPT charge controller using zeta converter with solar Photovoltaic (PV) system, Journal of Physics: Conference Series, Vol. 1432, 2020. 